\title{
Intrapersonal and Interpersonal Correlates of Condom Use among Young Adults from Continuation High Schools
}

\author{
Lilia Espinoza ${ }^{1}$, Jean L. Richardson ${ }^{2}$, Kristin Ferguson ${ }^{3}$, Chih-Ping Chou ${ }^{2}$, Lourdes Baezconde- \\ Garbanati $^{2}$, and Alan W. Stacy ${ }^{4}$ \\ ${ }^{1}$ Department of Health Science, California State University Fullerton \\ ${ }^{2}$ Department of Preventive Medicine, Institute for Prevention Research, University of Southern \\ California \\ ${ }^{3}$ School of Social Work, Arizona State University \\ ${ }^{4}$ School of Community \& Global Health, Claremont Graduate University
}

\begin{abstract}
Background and Purpose: Youth from continuation high schools (CHS) exhibit riskier sexual behaviors than other high school youth, yet the associations between intrapersonal and interpersonal constructs and condom-using behavior are not fully understood within this population. It is unknown which of these variables may be more strongly associated with condom use. This study explored the effects of parentadolescent communication, perceived HIV susceptibility, condom use peer norms, and condom use selfefficacy on lifetime and recent condom use and the potential moderating effects by gender and Latino ethnicity. Methods: A non-experimental study was conducted with 111 CHS young adults in Southern California who previously participated in a substance abuse prevention intervention. Ordinal logistic regression models assessed the associations between each construct and condom use and included interaction terms by gender and Latino ethnicity. Results: Parent-adolescent communication during adolescence and within the past 6 months as well as peer norms that support condom use were significantly associated with lifetime and recent condom use. Perceived HIV risk and condom use selfefficacy showed no effect. Relationships were not moderated by gender or Latino ethnicity. Conclusion: Findings highlight the salutary influence of parents and peers on personal condom use. Future research should explore intrapersonal factors that may motivate consistent condom use.

(C) 2017 Californian Journal of Health Promotion. All rights reserved.

Keywords: condom use, condom use self-efficacy, continuation high schools, parent-adolescent communication, peer norms, perceived susceptibility
\end{abstract}

\section{Introduction}

Sexual risk-taking behaviors have decreased over time among high school youth (CDC, 2015), but changes in sexual risk behaviors among adolescents from continuation high schools (CHS) are unknown. About 292,000 or $2 \%$ of high school youth in the United States attend a CHS or an alternative high school each academic year (National Center for Education Statistics, 2016). Adolescents are transferred to a CHS when they are at risk of not completing high school for various reasons (e.g., poor academic performance, truancy, disciplinary problems, pregnancy) and to fulfill an educational mandate (Carver \& Lewis, 2010).
Although CHS provide a structured setting to meet their needs (Carver \& Lewis, 2010), CHS youth are exposed to a social environment with greater sexual risk-taking behaviors. Based on aged data, CHS youth are more likely to have had sexual intercourse and be currently sexually active than other high school youth (Centers for Disease Control and Prevention [CDC], 1998; CDC, 1999; Coyle et al., 2006; Coyle et al., 2013; Tortolero et al., 2008). Over 1 in 5 new HIV diagnoses in 2014 were in adolescents and young adults, ages 13 to 24 years (Centers for Disease Control and Prevention [CDC], 2015). Consistent condom use during sexual intercourse is a primary HIV prevention strategy 
(Committee on Adolescence, 2013), yet CHS youth are less likely to report condom use at last sexual intercourse (CDC, 1998; CDC, 1999; Coyle et al., 2006; Coyle et al., 2013; Tortolero et al., 2008) and more likely to have either been pregnant or gotten someone pregnant, a marker of unprotected sexual intercourse (CDC, 1998; CDC, 1999; Tortolero et al., 2008).

\section{Sexual behaviors by Race/ethnicity and Gender}

Sexual behaviors among CHS youth vary by race/ethnicity and gender. Compared to Whites and Latinos, African American youth are more likely to be sexually experienced, currently sexually active, and have been pregnant or gotten someone pregnant, but they are also more likely to have used a condom at last sexual intercourse (CDC, 1999). Latino CHS youth are more likely to have had unprotected sex at last encounter and have higher pregnancy rates than non-Latino CHS youth (CDC, 1999), and differences may reflect varying acculturative levels (Haderxhanaj et al., 2014; Ma et al., 2014; Roncancio, Ward, \& Berenson, 2012; Smith, 2015). Although sexual activity is similar for males and females, females are least likely to report condom use and more likely to report pregnancy as an outcome (CDC, 1999). Adolescent pregnancy is a significant risk factor for high school dropout (Kearney \& Levine, 2012) and can exacerbate an already precarious academic situation in CHS female youth.

\section{Intrapersonal and Interpersonal Correlates of Condom Use}

Behavioral theories provide a framework by which intrapersonal and interpersonal constructs can influence sexual behaviors. Perceptions may be predisposing factors of risk behaviors (Janz \& Becker, 1984); however, intrapersonal factors alone do not provide an adequate description of risk as perceptions and behaviors are affected by the social environment (Baranowski, Perry, \& Parcel, 2002). Social interactions with sexual partners, peers and family members impact whether or not an individual will engage in safer sex through modeling and reinforcements (Bandura, 2004).
Intrapersonal Correlates of Condom Use. Perceived susceptibility is a central intrapersonal construct in several health behavior theories (Bandura, 2004; Janz \& Becker, 1984) that has been used to measure one's perception of risk or vulnerability for contracting HIV. Recent literature that explores the relationship between perceived HIV susceptibility and condom-using behavior among adolescents and young adults is aged and sparse. Perceiving HIV vulnerability has influenced condom use among African American and Latino adolescent and young adult males (Brooks, Lee, Stover, \& Barkley, 2011; Kennedy et al., 2007). Buzi, Smith, Weinman, and Novello (2013) found that females utilizing family planning clinics and with low HIV risk perception are more likely to be Latina and exhibit lower risk behaviors (e.g., fewer sexual partners), but their use of condoms is unknown. When the relationship between perceived susceptibility and condom use is explored among females, perceived susceptibility is tailored to pregnancy or sexually transmitted infections [STI]. Condoms are used as part of a dual-method contraceptive approach to prevent pregnancy (Lemoine, Teal, Peters, \& Guiahi, in press; Williams \& Fortenberry, 2013) or a STI which does not always include HIV (Cipres et al., 2017; Lemoine, Teal, Peters, \& Guiahi, in press; Matson, Chung, Huettner, \& Ellen, 2014; Williams \& Fortenberry, 2013). Females with low perceived HIV vulnerability exhibit a highrisk profile (e.g., condomless sex, STI occurrence), highlighting dissonance between perceptions and behaviors.

Peer norm perceptions are important contributors to shaping behaviors, and perceived approval of condom use by important referent peers may influence personal condom use (Fishbein, 1990). However, findings on this relationship are mixed. African American adolescents who perceive their close friends as holding anti-condom sentiments have inconsistent condom use (Dolcini et al., 2013). Latino males and females who perceive peer norms supporting condom use are more likely to report consistent condom usage (Kapadia et al., 2012), but Latinas also have a perceived low HIV risk (Buzi et al., 2013). Peer norms have 
also been shown to have no relationship with condom use among ethnically diverse CHS youth (Coyle et al, 2006; Coyle et al, 2013), African American females (Crosby et al., 2013), and rural adolescents (Haley, Puskar, Terhorst, Terr, \& Charron-Prochownik, 2012).

Interpersonal Correlates of Condom Use. Self-efficacy is a central construct of several intrapersonal and interpersonal health behavior theories (Ajzen, 1985; Bandura, 1994; Bandura, 2004) where different aspects of it have been measured in sexual behavior research. Condom use self-efficacy measures one's confidence in their ability to perform safer sex via condoms (Bandura, 1994) and is influenced by social interactions and experiences. It includes negotiating condom use with a sexual partner and the mechanics of placing a condom (Brafford \& Beck, 1991). Persons with greater self-efficacy for condom use (Haley et al., 2012; Shneyderman \& Schwartz, 2012) or condom negotiation (Crosby et al., 2013) are more likely to report condom use. For Latinos, embracing Latino cultural values (a distal construct of acculturation) is associated with greater condom use-self-efficacy whereas identifying more with American cultural values is related to less condom use (Ma et al., 2014). Findings vary when self-efficacy includes or is solely defined by condom mechanics. Among rural White adolescents, self-efficacy that includes both negotiation and mechanics is correlated with but is not predictive of condom use (Haley et al., 2012). Sexual risk-reduction interventions that have targeted increasing condom mechanics self-efficacy in CHS youth are limited and have shown either short-term marginal significance (Coyle et al., 2013) or significance for the control group only (Coyle et al., 2006).

By communicating on sex and sex-related topics with adolescents, parents convey the importance of engaging in open conversations on sexuality while relaying sexual health information (Widman, Choukas-Bradley, Noar, Nesi, \& Garrett, 2016). Parent-adolescent communication is significantly associated with condom use in some adolescent samples (Aspy et al., 2007; Hadley et al., 2009; Widman et al., 2016) but not in other samples (Haley et al.,
2012; Somers \& Ali, 2009). Discrepant findings may be due to methodological approaches that vary by sexual communication content, which parent delivers the information, and gender of the adolescent (Guilamo-Ramos, Lee, \& Jaccard, 2016). Adolescents use condoms when parent-adolescent discussions focus specifically on condoms (Aspy et al., 2007; Hadley et al., 2009) versus a general discussion on sexuality (Haley et al., 2012; Somers \& Ali, 2009). In a meta-analysis by Widman et al. (2016), larger effects of parent-adolescent communication on condom use are observed when mothers engage youth in discussions, when discussions focus on condoms and HIV, and when the recipients are female. Although parent-adolescent communication has been shown to have an indirect effect on condom use in Latino youth (Malcolm et al., 2012), an overall marginal relationship between parent-adolescent communication and condom use exists for Latino youth (Widman et al., 2016), reflecting that the relationship between parent-adolescent communication and condom use may be influenced by generational status (Deutsch \& Crockett, 2015) and traditional Latino cultural aspects that may not support open sexual-based dialogue (Guilamo-Ramos et al., 2006).

\section{Current Study}

Previous research has explored the relationships between various intrapersonal and interpersonal constructs and condom use in several adolescent samples. However there is a paucity of research on these relationships among CHS youth, a group who is exposed to and exhibits greater sexual risk behaviors than youth from high schools (CDC, 1999), and how these relationships may be moderated by race/ethnicity and gender. By being in a social environment with risky behaviors, CHS youth may perceive themselves as being at high risk for HIV and may be confident in their ability to use a condom even though they are surrounded by peers who do not support condom use. Additionally because CHS youth are in an atrisk academic situation, parents may communicate with them more frequently about sex in order to mitigate an already precarious situation. Therefore, the purpose of this study was to assess the relationships between 
perceived susceptibility to HIV, peer norms on condom use, condom use self-efficacy, and parent-adolescent communication on sexual safety and lifetime and recent condom use among former CHS youth. It was hypothesized that perceived HIV vulnerability, peer norms that support condom use, condom use self- efficacy, and parent-adolescent communication would be positively associated with condom use among CHS young adults. It was further hypothesized that these relationships would be moderated by Latino ethnicity and gender (Figure 1).

Figure 1

Conceptual Model of Frequency of Condom Use among Young Adults from Continuation High Schools.

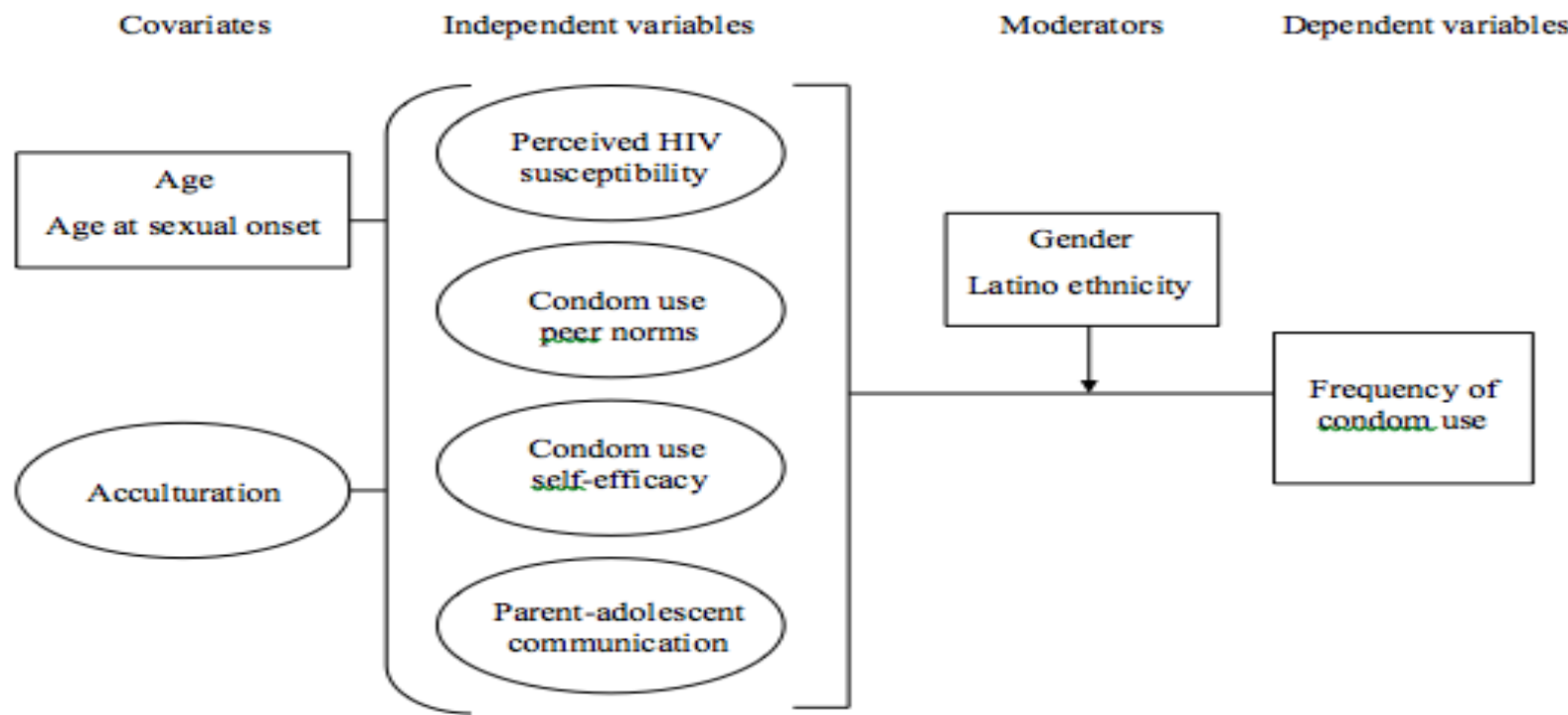

\section{Methods}

\section{Study Design}

The current study utilized a non-experimental study design to explore the relationships between intrapersonal and interpersonal constructs and condom use. The independent variables were perceived susceptibility to HIV, peer norms on condom use, condom use selfefficacy, and parent-adolescent communication on sexual safety, and the dependent variables were lifetime and recent condom use. Additionally, Latino ethnicity and gender were explored as moderators on each relationship.

\section{Participants}

A sample of young adults who participated in an earlier study on substance use prevention (Sussman, Dent, \& Stacy, 2002; Valente et al., 2007) was approached for the current study. Participants were originally recruited from 14 continuation high schools in southern California for a parent study that explored the roles of associative memory and implicit cognition on substance use among at-risk youth. Information on sexual behaviors among CHS youth was not collected, warranting a separate study.

Inclusion criteria for the current study were a minimum age of 18 years at the time of sampling and self-identified Latino, White, or African American $(N=747)$. Whites, African Americans and females were oversampled in order to test for interactive effects of race/ethnicity and gender. The sample size was also limited to individuals who had contact information and the name of at least one parent or guardian for whom online searches could be completed to obtain updated information. The final base sample was reduced further to 391 potential participants of which a convenience sample of 111 former CHS youth were interviewed for the current study. 


\section{Procedures}

Eligible individuals from the parent study $(N=$ 391) were sent a letter signed by the principal investigator of the parent study notifying them of the new telephone-based study. They were given the option to not be contacted by study staff by returning a postage-paid postcard with their decision to not participate. Those persons who did not return a postcard by a certain date were eligible for the study. Online database searches (e.g., White Pages, PeopleFinders) were made using available contact information to update addresses and phone numbers. Participants were considered unable to locate if the contact information was no longer valid, and updated information was unavailable. A minimum of 10 phone call attempts was made to each participant before being labeled as "unable to reach."

When the participant was reached by telephone, an initial screener with verbal consent was read giving general information on the survey. The 15-minute survey was administered by a trained interviewer once the participant consented verbally to participate. Participants were reminded of confidentiality procedures and were given the option to refuse to answer any sexual behaviors questions in order to minimize response biases. A $\$ 15$ gift card as remuneration was mailed to each participant for completing a survey. All materials and procedures received human subjects' approval from the Institutional Review Board at the University of Southern California's Health Sciences Campus.

\section{Measures}

Dependent Variables. Frequencies of lifetime and recent condom use during anal and/or vaginal intercourse were assessed as separate outcome variables. Two single-item indicator variables measured the frequency of condom usage during anal and/or vaginal sex over one's lifetime and within the past 3 months (Fishbein $\&$ Coutinho, 1997). The response format was a 5-point Likert-type scale, and each item was reverse-coded so that a higher rating (' 5 ') indicated consistent condom use.
Independent Variables. Exploratory factor analyses were performed to select reliable items and create scales for the intrapersonal and interpersonal constructs. Items with a minimum factor loading of 0.40 on at least one factor were retained in the final scale. Each final scale was the weighted sum of the products of the values of the variables and their factor loadings and was included in regression analyses.

Perceived HIV Susceptibility. The Health Belief Model Perceived Susceptibility (HMBP) scale (Lux \& Petosa, 1994) was a 6-item scale assessing perceived susceptibility to HIV. The statements pertained to perceptions that people similar to self in age or other ways do not get HIV; peers and self are too young to get HIV; one's good health can fight HIV infection; and small personal concern over contracting HIV. The statements were on a 4-point Likert-type scale assessing level of agreement to each statement. A higher summative score on the final perceived HIV risk scale $(\alpha=0.84)$ indicated greater perceived HIV susceptibility.

Peer Norms for Condom Use. The Sexual Risks Scale-Norms (SRSN) scale was a 7-item scale that assessed peer norms for condom use (DeHart \& Birkimer, 1997). Statements pertained to peer anger or disappointment in self for not using a condom; frequent communication on safer sex; peer encouragement to practice safer sex; peer concern over condom use; mutual communication on carrying a condom ( 2 items); and communication on whether or not a condom was used during sexual activity. The item on peer concern over condom use was reversecoded to be positively oriented. Statements were on a 5-point Likert-type scale assessing level of agreement to each statement. A higher summative score on the final scale $(\alpha=0.90)$ indicated peer norms supporting condom use.

Condom Use Self-efficacy. The Condom Use Self-Efficacy Scale (CUSES) was a 7-item scale that assessed the mechanics of putting a condom on self or other (4 items) and one's ability to negotiate condom use (3 items; Brafford \& Beck, 1991). All items were reverse-coded to be positively oriented. Statements were on a 5- 
point Likert-type scale assessing level of agreement to each statement. A higher summative score on the final scale $(\alpha=0.94)$ indicated greater condom use self-efficacy.

Parent-adolescent Communication. The Parent-Adolescent Communication Scale (PACS) was a 5-item scale assessing an adolescent's frequency of sexual communication with a parent or guardian in the previous 6 months (McDermott Sales et al., 2008). The topics were sex, how to use condoms, protecting self from STIs, protecting self from HIV, and preventing pregnancy. Each statement was on a 4-point Likert-type scale and assessed the frequency of communication per topic. PACS was used to assess sexual communication within the 6 months prior to the survey and was then modified to retrospectively assess communication during the participant's adolescent years. A higher summative score in each final scale ( $\alpha=0.91$, each) indicated more frequent parent-adolescent sexual communication. Dichotomous variables were also created for each of the sexual communication topics and by time period where any communication ('1) was compared to no communication (' 0 ').

Covariates. Demographic data on gender and ethnicity were collected during the baseline assessment (Valente et al., 2007). Males ('1') were compared to females (' 0 '), and Latinos (' 1 ') were compared to non-Latinos (' 0 '). Each variable was assessed as a moderator. Information on age and linguistic acculturation were collected for the current study. Age in years was computed using birth and interview dates. Linguistic acculturation was measured using the Marín et al. (1987) short acculturation scale that addressed the extent to which languages (i.e., English, Spanish) were most often read and spoken; spoken at home; spoken with friends; and to which movies, television, and radio shows were watched and listened. The final acculturation score $(\alpha=0.88)$ was the mean value of the four items with a lower score ('1') reflecting English preference and greater acculturation.
Data on sexual behaviors were collected for the current study. Age at sexual onset was collected using an ordinal measure and dichotomized at the median age of 15 years. An earlier age at sexual initiation (i.e., $\leq 15$ years) was coded as '1.' Sexual behavior orientation was defined using gender; self-identified sexual orientation; and reported gender(s) of lifetime and recent sexual partners. The three sexual behavior orientation categories were men who had sex with both men and women (' 1 '), women who had sex with men and/or women ('2'), and men who had sex with women (' 3 '). A male was coded as behaviorally having had sex with both men and women (' 1 ') if he self-identified as "heterosexual" but engaged in sex with both males and females.

Data on the numbers of lifetime and recent (i.e., past 3 months) sexual partners were collected using open-ended questions (CDC, 2008). Sexual partners were defined as any partner with whom the participant engaged in anal, receptive oral, and/or vaginal intercourse in one's lifetime and in the past 3 months. The number of recent partners was coded as ' 0 ' for participants who had sex but not recently. Number of lifetime partners was a covariate in models predicting lifetime condom use whereas number of recent partners was a covariate in models predicting condom use in the past 3 months.

\section{Analyses}

Frequency distributions, means, standard deviations, medians, and quartiles were computed to describe demographics; sexual onset characteristics; perceived susceptibility to HIV; peer norms on condoms; condom use selfefficacy; parent-adolescent communication on sexual safety; and frequencies of lifetime and recent condom use. Independent samples $t$-tests were conducted to compare gender and Latino ethnicity on each intrapersonal or interpersonal construct. Mann-Whitney $U$ tests were conducted to explore the relationships between gender and Latino ethnicity and the ordinal variables of lifetime and recent condom use. McNemar's test was used to compare frequencies of parent-adolescent communication by topic during adolescence and in the past 6 months. Pearson's correlation coefficients were 
calculated to explore bivariate relationships between acculturation and sexual safety topics among Latinos as well as between and among parent-adolescent communication, perceived susceptibility to HIV, condom use peer norms, condom use self-efficacy, and lifetime and recent condom use, stratified by gender and Latino ethnicity.

Separate ordinal logistic regression models were run to assess whether or not each intrapersonal or interpersonal factor was associated with lifetime and recent condom use during anal and/or vaginal sex. Interaction terms were included separately for each independent variable and covariate (i.e., gender, Latino ethnicity) in order to evaluate if there was a difference in condom use by levels of the potential moderator. The criterion for statistical significance was set to a 0.05 level. Measures of reliability, descriptive statistics, correlations, and regression analyses were computed using SAS version 9.4.

\section{Results}

A total of 111 former CHS young adults participated in the study (Table 1). The sample was mostly Latino (56.8\%), female (50.5\%), and heterosexual (96.4\%) with a mean age of 20.6 years. The majority of the sample were sexually experienced $(98.2 \%)$ and initiated sex by age 15 years $(58.9 \%)$. Non-Latinos were more likely than Latinos to have an early age at sexual onset $\left[\chi^{2}(1, N=107)=7.09, p<.01\right]$. Compared to males, females were more likely to perceive themselves as susceptible to HIV $[t(93.5)=2.07$, $p=.04]$, but their condom use self-efficacy was significantly lower $[t(100.8)=-3.20, p<.01]$.

Table 1.

Characteristics of the Sample

\begin{tabular}{|c|c|c|c|c|c|c|c|c|c|c|c|}
\hline \multirow[t]{2}{*}{ Variable } & \multicolumn{2}{|c|}{$\begin{array}{l}\text { Overall } \\
\mathrm{N}=111\end{array}$} & \multicolumn{2}{|c|}{$\begin{array}{c}\text { Female } \\
\mathrm{N}=56\end{array}$} & \multicolumn{2}{|c|}{$\begin{array}{l}\text { Male } \\
\mathrm{N}=55\end{array}$} & \multicolumn{2}{|c|}{$\begin{array}{l}\text { Latino } \\
\mathrm{N}=63\end{array}$} & \multicolumn{2}{|c|}{$\begin{array}{c}\text { Non-Latino }^{\mathrm{a}} \\
\mathrm{N}=48\end{array}$} & \\
\hline & $\mathrm{N}$ & $\%$ & $\mathrm{~N}$ & $\%$ & $\mathrm{~N}$ & $\%$ & $\mathrm{~N}$ & $\%$ & $\mathrm{~N}$ & $\%$ & \\
\hline \multicolumn{12}{|l|}{ Ever had sex } \\
\hline Lifetime & 109 & 98.2 & 55 & 98.2 & 54 & 98.2 & 61 & 96.8 & 48 & 100.0 & \\
\hline Past 3 months & 103 & 92.8 & 52 & 92.9 & 51 & 92.7 & 51 & 81.0 & 43 & $(89.6)$ & \\
\hline $\begin{array}{l}\text { Age at first } \\
\text { sex, } \leq 15 \text { years }\end{array}$ & 63 & 58.9 & 34 & 64.2 & 29 & 53.7 & 28 & 47.5 & 35 & 72.9 & \\
\hline \multicolumn{12}{|c|}{ Sexual orientation ${ }^{\mathrm{b}}$} \\
\hline MSM & 4 & 3.6 & --- & --- & 4 & 7.3 & 3 & 4.8 & 1 & 2.1 & \\
\hline WSM & 56 & 50.5 & 56 & 100.0 & --- & --- & 33 & 52.4 & 23 & 47.9 & \\
\hline \multirow[t]{2}{*}{ MSW } & 51 & 45.9 & --- & --- & 51 & 92.7 & 27 & 42.9 & 24 & 50.0 & \\
\hline & Mean & SD & Mean & SD & Mean & SD & Mean & SD & Mean & SD & Range $^{\mathrm{c}}$ \\
\hline Age (years) & 20.56 & 1.24 & 20.27 & 1.27 & 20.85 & 1.14 & 20.57 & 1.19 & 20.54 & 1.32 & $18-23$ \\
\hline Acculturation & 1.83 & 0.89 & 1.88 & 0.94 & 1.78 & 0.84 & 2.44 & 0.71 & 1.03 & 0.12 & $1-5$ \\
\hline $\begin{array}{l}\text { PAC, }{ }^{\text {d }} \text { past } 6 \\
\text { months }\end{array}$ & 7.81 & 3.86 & 8.29 & 4.04 & 7.32 & 3.65 & 8.15 & 3.93 & 7.35 & 3.76 & $5-20$ \\
\hline $\begin{array}{l}\text { PAC, } \\
\text { adolescence }\end{array}$ & 9.44 & 4.02 & 9.16 & 4.01 & 9.73 & 4.04 & 8.72 & 3.86 & 10.40 & 4.05 & $5-20$ \\
\hline $\begin{array}{l}\text { Perceived HIV } \\
\text { susceptibility }\end{array}$ & 16.46 & 2.44 & 16.93 & 1.88 & 15.98 & 2.84 & 16.26 & 2.51 & 16.71 & 2.35 & $6-24$ \\
\hline $\begin{array}{l}\text { Condom use } \\
\text { peer norms }\end{array}$ & 19.69 & 4.87 & 19.97 & 4.49 & 19.40 & 5.25 & 19.56 & 4.79 & 19.86 & 5.02 & $7-35$ \\
\hline $\begin{array}{l}\text { Condom use } \\
\text { self-efficacy }\end{array}$ & 25.38 & 4.05 & 24.22 & 4.43 & 26.57 & 3.24 & 25.40 & 3.61 & 25.36 & 4.60 & $7-35$ \\
\hline & Med. & Q1,Q3 & Med. & Q1,Q3 & Med. & Q1,Q3 & Med. & Q1,Q3 & Med. & Q1,Q3 & Range \\
\hline \multicolumn{12}{|c|}{ Condom use frequency } \\
\hline Lifetime & 4 & 3,4 & 3 & 3,4 & 4 & 3,4 & 3 & 3,4 & 4 & 3,4 & $1-5$ \\
\hline Past 3 months & 2 & 1,3 & 2 & 1,3 & 2 & 1,4 & 2 & 1,3 & 2 & 1,3 & $1-5$ \\
\hline
\end{tabular}


Participants were more likely to talk about unplanned pregnancies with a parent during their adolescent years $(77.9 \%)$ than in the past 6 months $\left(55.1 \% ; \chi^{2}(1, N=109)=18.94, p\right.$ $<.0001)$. Participants and parents were also more likely to talk about sex during adolescent $(75.2 \%)$ versus young adult years $\left(53.2 \% ; \chi^{2}(1\right.$, $N=109)=16.94, p<.0001)$. How to use condoms was the least discussed topic $(44.9 \%$ and $28.4 \%$, respectively). Non-Latinos more likely to talk with a parent on sexual safety than
Latinos $[t(109)=2.22, p=.03]$. When Latino parent-adolescent dyads talked about sexual safety, these conversations occurred among more acculturated Latinos and focused on STI prevention during their adolescent years $[r(61)=$ $-.26, p=.04]$. Overall, participants reported using condoms most of the time in their lifetime and rarely in the past 3 months, and condom use did not differ by gender or Latino ethnicity. More acculturated Latinos reported greater lifetime condom use $[r(59)=-.27, p=.03]$

Table 2.

Bivariate Correlations among Study Variables by Gender ${ }^{\mathrm{a}}$

\begin{tabular}{|c|c|c|c|c|c|c|c|}
\hline Variable & 1 & 2 & 3 & 4 & 5 & 6 & 7 \\
\hline 1. PACS, past 6 months ${ }^{b}$ & 1.00 & $.43^{* * *}$ & .01 & .13 & .02 & $.25^{\dagger}$ & $.37^{* * *}$ \\
\hline 2. PACS, adolescent years & $.63^{* * *}$ & 1.00 & $.27^{*}$ & $.25^{\dagger}$ & .18 & $.35^{* *}$ & $.32^{*}$ \\
\hline 3. Perceived HIV susceptibility & -.15 & .02 & 1.00 & $.55^{* * *}$ & .19 & $.32^{*}$ & -.20 \\
\hline 4. Peer norms on condom use & $.23^{\dagger}$ & .14 & .09 & 1.00 & $.45^{* *}$ & $.29^{*}$ & -.14 \\
\hline 5. Condom use self-efficacy & $.24^{\dagger}$ & $.26^{\dagger}$ & .04 & $.56^{* * * *}$ & 1.00 & .03 & -.06 \\
\hline 6. Condom use, lifetime ${ }^{c}$ & $.26^{\dagger}$ & .22 & -.18 & $.43^{* *}$ & $.35^{* * *}$ & 1.00 & $.41^{* *}$ \\
\hline 7. Condom use, past 3 months ${ }^{\mathrm{c}}$ & $.25^{\dagger}$ & .10 & $-.30^{*}$ & $.24^{\dagger}$ & .09 & $.49^{* *}$ & 1.00 \\
\hline
\end{tabular}

${ }^{\mathrm{a}}$ Values for males are above the diagonal.

${ }^{\mathrm{b}}$ PACS: Parent-adolescent communication on sex

${ }^{\mathrm{c}}$ Limited to those who have ever had sexual intercourse $(\mathrm{n}=109)$.

${ }^{\dagger} p<.10,{ }^{*} p<.05,{ }^{* *} p<.01,{ }^{* * *} p<.001$

Select intrapersonal and interpersonal constructs were significantly correlated with condom use with differences by gender (Table 2) and Latino ethnicity (Table 3). For females and nonLatinos, greater condom use self-efficacy was correlated with more consistent lifetime condom use. Although perceived HIV risk at the time of the survey was high for females and Latinos, their recent condom use was not consistent.
Latinos who recently spoke with a parent on sexual safety were more likely to consistently use condoms in the past 3 months. Males and non-Latinos who talked more with a parent about sexual safety during adolescence reported more consistent lifetime and recent condom use. Males with higher perceived risk for HIV and non-Latinos whose peers support condom use reported more consistent lifetime condom use.

Table 3.

Bivariate Correlations among Study Variables by Ethnicity

\begin{tabular}{|c|c|c|c|c|c|c|c|}
\hline Variable & 1 & 2 & 3 & 4 & 5 & 6 & 7 \\
\hline 1. PACS, past 6 months $^{b}$ & 1.00 & $.57^{* * * *}$ & -.10 & .01 & .02 & $.25^{\dagger}$ & $.40^{* * *}$ \\
\hline 2. PACS, adolescent years & $.53^{* * *}$ & 1.00 & .11 & -.01 & .10 & .16 & 144 \\
\hline 3. Perceived HIV susceptibility & .07 & .17 & 1.00 & $.33^{* *}$ & .04 & .03 & $-.32^{*}$ \\
\hline 4. Peer norms on condom use & $.44^{* *}$ & $.44^{* *}$ & $.44^{* *}$ & 1.00 & $.41^{* *}$ & .18 & -.09 \\
\hline 5. Condom use self-efficacy & .21 & $.37^{* *}$ & .06 & $.51^{* *}$ & 1.00 & .03 & -.05 \\
\hline 6. Condom use, lifetime ${ }^{c}$ & $.28^{\dagger}$ & $.44^{* *}$ & $.24^{\dagger}$ & $.60^{* * *}$ & $.43^{* *}$ & 1.00 & $.41^{* *}$ \\
\hline 7. Condom use, past 3 months ${ }^{\mathrm{c}}$ & .14 & $.33^{*}$ & -.12 & .17 & .17 & $.33^{*}$ & 1.00 \\
\hline
\end{tabular}

${ }^{a}$ Values for Latinos are above the diagonal. ${ }^{b}$ Further adjusted for number of sexual partners in past 3 months

${ }^{\mathrm{b}}$ PACS: Parent-adolescent communication on sex

${ }^{c}$ Limited to those who have ever had sexual intercourse $(\mathrm{n}=109)$.

${ }^{\dagger} p<.10,{ }^{*} p<.05,{ }^{* *} p<.01,{ }^{* * *} p<.001$

After controlling for covariates in ordered logistic regressions, parent-adolescent communication on sexual safety during adolescence (adjusted odds ratio $[\mathrm{aOR}]=1.15$; 
95\% CI: $[1.04,1.28])$ and within the past 6 months $(\mathrm{aOR}=1.11 ; 95 \% \mathrm{CI}:[1.01,1.23])$ and peer norms that support condom use $(\mathrm{aOR}=$ $1.17 ; 95 \%$ CI: $[1.07,1.28])$ remained significantly associated with lifetime condom use (Table 4). Recent sexual safety communication $(\mathrm{aOR}=1.19 ; 95 \% \mathrm{CI}$ : $[1.07$, $1.32])$, communication during adolescence (aOR $=1.24 ; 95 \% \mathrm{CI}:[1.12,1.38])$ and condom use peer norms $(\mathrm{aOR}=1.11 ; 95 \% \mathrm{CI}$ : $[1.01,1.21])$ were also associated with recent condom use. Perceived susceptibility to HIV and condom use self-efficacy were not associated with condom use. Interactions of gender and Latino ethnicity with each psychosocial construct were examined; however, no interactions were statistically significant.

Table 4.

Ordered Logistic Regression Predicting Condom Use Frequency of Condom use, Anal/vaginal Sex Lifetime $^{\mathrm{a}} \quad$ Past 3 Months

\begin{tabular}{ccc}
\multicolumn{2}{c}{$(N=109)$} & \multicolumn{2}{c}{$(N=103)$} \\
\hline Adjusted & $95 \%$ & Adjusted $95 \%$
\end{tabular}

\begin{tabular}{lcccc} 
& OR & CI & OR & CI \\
\hline & & & & \\
\hline PACS, & $\mathbf{1 . 1 5}^{* *}$ & 1.04, & $\mathbf{1 . 2 4}^{* * *}$ & 1.12, \\
adolescence & & 1.28 & & 1.38
\end{tabular}

\begin{tabular}{|c|c|c|c|c|}
\hline adolescence & $1.15^{* *}$ & 1.28 & 1.24 & 1.38 \\
\hline $\begin{array}{l}\text { PACS, past } \\
6 \text { months }\end{array}$ & $1.11^{*}$ & $\begin{array}{l}1.01, \\
1.23\end{array}$ & $1.19^{* *}$ & $\begin{array}{l}\text { 1.07, } \\
1.32\end{array}$ \\
\hline $\begin{array}{l}\text { Perceived } \\
\text { HIV } \\
\text { susceptibility }\end{array}$ & 1.00 & $\begin{array}{l}0.85 \\
1.18\end{array}$ & 0.92 & $\begin{array}{l}0.78, \\
1.09\end{array}$ \\
\hline $\begin{array}{l}\text { Peer norms } \\
\text { on condom } \\
\text { use }\end{array}$ & $1.17^{* *}$ & $\begin{array}{l}1.07 \\
1.28\end{array}$ & $1.11^{*}$ & $\begin{array}{l}1.01, \\
1.21)\end{array}$ \\
\hline $\begin{array}{l}\text { Condom use } \\
\text { self-efficacy }\end{array}$ & 1.10 & $\begin{array}{l}0.99 \\
1.22 \\
\end{array}$ & 1.07 & $\begin{array}{c}0.96 \\
1.19\end{array}$ \\
\hline \multicolumn{5}{|c|}{$\begin{array}{l}p<.05, p<.01, \quad p<.001 \\
\text { Note. Models are adjusted for age, gender, } \\
\text { race/ethnicity, age at sexual debut, and acculturation. } \\
\text { âFurther adjusted for lifetime number of sexual } \\
\text { partners }\end{array}$} \\
\hline
\end{tabular}

\section{Discussion}

An exploration of the relationships between several intrapersonal and interpersonal constructs and frequencies of condom use revealed that some constructs are more salient than other constructs in influencing condom use. Unlike Lemoine, Teal, Peters, and Guiahi (in press) who found that females who did not use condoms had low perceived vulnerability to HIV, females from the current study perceived themselves as susceptible to HIV. However, their recent condom use was low, highlighting a seemingly dissonant relationship between perceived susceptibility to HIV and recent condom. Upon further exploration, this negative relationship maintained for females with one sexual partner and lower HIV risk factors (i.e., self-reported monogamy).

There are many possible reasons for the apparent discrepancy between perception of HIV risk and condom use. Lower risk individuals may acknowledge the potential for HIV risk regardless of one's safer sex behaviors. They may not think that they are at risk for HIV but are not ruling out the possibility that they are at risk for HIV simply because they are young. Since they are more aware of the potential risk, safer sexual behaviors are selected (e.g., monogamy; a low-risk profile as in Buzi, Smith, Weinman, \& Novello, [2013]). Also, perceived HIV risk is known among the sample, but the likelihood of HIV infection, a potential moderator of the relationship, is unknown. Second, individuals could have underreported sexual risk behaviors compromising the validity of the data. However, participants were assured of the confidentiality of all data, and measures were taken to confer this confidentiality. Furthermore, measures that were used had been validated previously in adolescent samples. Thus, there is no reason to believe that participants were differentially dishonest in their answers. Finally, individuals may also suspect or know that their sexual partner has other sexual partners which is information that was not collected. Although choosing monogamy, a partner's sexual practices pose an HIV risk to the study participant. Lack of consistent condom use in light of these thoughts further poses an HIV risk.

Peers also played a key role in condom use in that individuals who perceived peer norms as encouraging safer sex were more likely to practice safer sex in their lifetime. Regardless of 
gender and Latino ethnicity, peer networks that discussed and encouraged safer sex translated into more consistent condom use, supporting Kapadia et al.'s (2012) findings with a Latino adolescent sample and in contrast to Coyle et al.'s (2006) findings on ethnically diverse CHS youth.

Unlike prior research that also measured selfefficacy through mechanics and negotiation and found a positive association (Crosby et al., 2013; Haley et al., 2012; Shneyderman \& Schwartz, 2012), condom use self-efficacy had no effect on condom use after controlling for covariates. However, bivariate analyses revealed some interesting findings. Greater confidence in one's ability to use condoms was significantly correlated with peer norms and associated with consistent lifetime condom use among females and Latinos. Having peers that encourage safer sex as well as having the ability to practice safer sex, which may be a skill learned and honed by talking with peers, may contribute to being more likely to use condoms consistently.

Participants rarely discussed sexual safety with a parental figure during adolescence, and communication was even rarer during young adulthood. The rank of the topics did not differ between the two time periods, and protecting against an unplanned pregnancy and sex in general were the most common topics discussed. However infrequent and unlike Haley et al. (2012) and Somers and Ali (2009), sexual safety communication between a parent and an adolescent was associated with a greater likelihood of consistent lifetime and recent condom use regardless of when the communication took place. Although Widman et al. (2016) found larger effects for adolescent females, the current findings do not support relationships moderated by gender. Communication was associated with condom use regardless of the recipient's gender.

Parent-adolescent communication also had a predictive effect. Young adults who reported greater frequency in communication with a parent during their adolescence, especially on the general topic of sex and how to avoid an unplanned pregnancy, reported more consistent lifetime and recent condom use at follow-up. In bivariate analyses, communication on sexual safety during adolescence was significantly lower in Latinos than non-Latinos but higher (albeit not significantly) in young adulthood. Among Latinos, parent-adolescent conversations occurred among more acculturated adolescents and focused on STI prevention. The initial small sample size does not provide sufficient statistical power for further stratification by gender. Any statistical difference was no longer apparent in ordered logistic regression models. Widman et al. (2016) also noted marginal effects of communication on condom use among Latino adolescents. With Widman et al.'s (2016) metaanalysis and the current findings, timing of communication appears to start later in Latino families. Latino cultural values such as simpatía (harmonious relationships) and respeto (respect) may act as protective factors of early sexual debut (Ma et al., 2014), evidenced by a significantly smaller proportion of Latino youth who initiated sex by age 15 years.

\section{Limitations}

Findings should be considered in light of additional study limitations. Causality cannot be deduced from these analyses due to their crosssectional nature. Most of the psychosocial items assessed current psychosocial. It is quite plausible that some behaviors may lead to social cognitions. For example lack of consistent recent condom use may have increased one's perception of HIV susceptibility. Furthermore, psychosocial constructs are dynamic and change over time in response to new environmental stimuli (e.g., knowledge, peers). However with the recent items, it makes theoretical sense to look at the association as psychosocial constructs leading to current sexual behaviors.

Although efforts were taken to contact a larger sample size, tracking participants was difficult, many of whom were lost to follow-up. The final sample size is representative of a CHS sample that is about 50\% Latino and 50\% female. However, participants were a convenient sample who were able to be contacted and agreed to participate in the study. Participants who were not interviewed may have sexual behaviors that differ from the current sample thereby limiting the generalizability of the findings. 


\section{Conclusion}

Results from this study support the association of key intrapersonal and interpersonal constructs on consistency of using condoms. These conclusions bear potential implications for the prevention of sexual risk-taking that place an individual at risk of HIV and other sexually transmitted diseases (STD). Interventions aimed at youth in continuation high schools could benefit by incorporating comprehensive sexual education into curriculum. Sexual education should not only focus on delaying sexual onset but also on using condoms correctly and consistently as a way of reducing one's risk of
HIV and other STD. Sexual education curriculum should also include information to enhance HIV knowledge and perception of risk (e.g., HIV prevalence among youth) while normalizing sexuality and its discussion among peers. Furthermore, interventions should include parental involvement. Parents and parental figures should be provided with the knowledge and tools on how to effectively communicate with children not only about HIV risk but also about sexuality in general. Future research is needed to determine whether this type of intervention can reduce sexual risk-taking among this at-risk population.

\section{References}

Ajzen, I. (1985). From intentions to actions: A theory of planned behavior. In J. Kuhl \& J. E. Beckmann (Eds.), Action-control: From cognition to behavior (pp. 11-39). Heidelberg, Germany: Springer.

Aspy, C. B., Vesely, S. K., Oman, R. F., Rodine, S., Marshall, L., \& McElroy, K. (2007). Parental communication and youth sexual behaviour. Journal of Adolescence, 30, 449-466.

Bandura, A. (1994). Social cognitive theory and exercise of control over HIV infection. In Preventing AIDS: Theories and methods of behavioral interventions. AIDS prevention and mental health, DiClemente, RJ, and Peterson, JL (Eds). New York: Plenum Press, pp 25-29.

Bandura, A. (2004). Health promotion by social cognitive means. Health Education and Behavior, 31, 143-164.

Baranowski, T., Perry, C. L., \& Parcel, G. S. (2002). How individuals, environments, and health behavior interact. In K. Glanz, B. K.. Rimer, \& F. M. Lewis (Eds.), Health Behavior and Health Education: Theory, Research, and Practice (pp. 165-184). San Francisco, CA: Jossey-Bass.

Brafford, L.J., \& Beck, K.H. (1991). Development and validation of a condom self-efficacy scale for college students. Journal of American College Health, 39, 219-225.

Brooks, R. A., Lee, S. J., Stover, G. N., \& Barkley, T. W. (2011). HIV testing, perceived vulnerability and correlates of HIV sexual risk behaviors of Latino and African American young male gang members. International Journal of STD and AIDS, 22(1), 19-24.

Buzi, R. S., Smith, P. B., Weinman, M. L., \& Novello, G. (2013). HIV risk perceptions among adolescents attending family planning clinics: An integrated perspective. AIDS Care, 25(1), 2027.

Carver, P. R., \& Lewis, L. (2010). Alternative Schools and Programs for Public School Students At Risk of Educational Failure: 2007-08. Washington: U.S. Department of Education, National Center for Education Statistics.

Centers for Disease Control and Prevention (1999). Youth Risk Behavior Surveillance - National Alternative High School Youth Risk Behavior Survey, United States, 1998. MMWR, 48(SSO7), 144.

Centers for Disease Control and Prevention (2000). Youth Risk Behavior Surveillance -United States, 1999. MMWR, 49(SSO5), 1-104.

Centers for Disease Control and Prevention (2008). 2007 State and Local Youth Risk Behavior [Survey]. Retrieved from ftp://ftp.cdc.gov/pub/data/yrbs/2007/2007_hs_questionnaire.pdf.

Centers for Disease Control and Prevention (2015). HIV/AIDS Surveillance Report, 2014, Vol. 26. Atlanta: U.S. Department of Health and Human Services, Centers for Disease Control and Prevention. 
Espinoza, L., Richardson, J.L., Ferguson, K., Chou, C.P, Baezconde-Garbanati, L., Stacy, A.W. / Californian Journal of Health

Promotion 2017, Volume 15, Issue 3, Pages 1-14.

Centers for Disease Control and Prevention (2016). Sexually Transmitted Disease Surveillance 2015. Atlanta: U.S. Department of Health and Human Services, Centers for Disease Control and Prevention.

Cipres, D., Rodriguez, A., Alvarez, J., Stern, L., Steinauer, J., \& Seidman, D. (2017). Racial/ethnic differences in young women's health-promoting strategies to reduce vulnerability to sexually transmitted infections. Journal of Adolescent Health, 60, 556-562.

Committee on Adolescence (2013). Condom use by adolescents. Pediatrics, 132(5), 973-981.

Coyle, K. K., Glassman, J. R., Franks, H. M., Campe, S., Denner, J., \& Lepore, G. (2013). Interventions to reduce sexual risk behaviors among youth in alternative schools: A randomized controlled trial. Journal of Adolescent Health, 53(1), 68-78.

Coyle, K.K., Kirby, D.B., Robin, L.E., Banspach, S.W., Baumler, E., \& Glassman, J.R. (2006). All4You! A randomized trial of an HIV, other STDs, and pregnancy intervention for alternative school students. AIDS Education and Prevention, 18(3), 187-203.

Crosby, R. A., DiClemente, R. J., Salazar, L. F., Wingood, G. M., McDermott-Sales, J., Young, A. M., \& Rose, E. (2013). Predictors of consistent condom use among young African American women. AIDS and Behavior, 17(3), 865-871.

DeHart, D. D., \& Birkimer, J. C. (1997). Trying to practice safer sex: development of the sexual risks scale. The Journal of Sex Research, 34, 11-25.

Deutsch, A. R., \& Crockett, L. J. (2015). Gender, generational status, and parent-adolescent sexual communication: Implications for Latino/a adolescent sexual behavior. Journal of Research on Adolescence, 26(2), 300-315.

Dolcini, M. M., Catania, J. A., Harper, G. W., Watson, S. E., Ellen, J. M., \& Towner, S. L. (2013). Norms governing urban African American adolescents' sexual and substance-using behavior. Journal of Adolescence, 36, 31-43.

Fishbein, M., \& Coutinho, R. (1997). NIMH Multisite HIV Prevention Trial. AIDS, 11, S2.

Guilamo-Ramos, V., Lee, J. J., \& Jaccard, J. (2016). Parent-adolescent communication about contraception and condom use. JAMA Pediatrics, 170(1), 14-16.

Guilamo-Ramos, V., Dittus, P., Jaccard, J., Goldberg, V., Casillas, E., \& Bouris, A. (2006). The content and process of mother-adolescent communication about sex in Latino families. Social Work Research, 30(3), 169-181.

Haderxhanaj, L. T., Dittus, P. J., Loosier, P. S., Rhodes, S. D., Bloom, F. R., \& Leichliter, J. S. (2014). Acculturation, sexual behaviors, and health care access among Hispanic and non-Hispanic white adolescents and young adults in the United States, 2006-2010. Journal of Adolescent Health, 55(5), 716-719.

Hadley, W., Brown, L. K., Lescano, C. M., Kell, H., Spalding, K., DiClemente, R., ... Project STYLE Study Group. (2009). Parent-adolescent sexual communication: Associations of condom use with condom discussions. AIDS and Behavior, 13(5), 997-1004.

Haley, T., Puskar, K., Terhorst, L., Terry, M. A., \& Charron-Prochownik, D. (2012). Condom use among sexually active rural high school adolescents personal, environmental, and behavioral predictors. Journal of School Nursing, 29, 212-224.

Janz, N., \& Becker, M. H. (1984). The health belief model: A decade later. Health Education Quarterly, $11,1-47$.

Kapadia, F., Frye, V., Bonner, S., Emmanuel, P. J., Samples, C. L., \& Latka, M. H. (2012). Perceived peer safer sex norms and sexual risk behaviors among substance-using Latino adolescents. AIDS Education and Prevention, 24(1), 27-40.

Kearney, M. S., \& Levine, P. B. (2012).Why is the teen birth rate in the United States so high and why does it matter? Journal of Economic Perspectives, 26, 141-163.

Kennedy, S. B., Nolen, S., Applewhite, J., Pan, Z., Shamblen, S., \& Venderhoff, K. J. (2007). A quantiatitve study on the condom-se behaviors of eighteen-to-twenty-four year-old urban African American males. AIDS Patient Care and STDs, 21(5), 306-321. 
Espinoza, L., Richardson, J.L., Ferguson, K., Chou, C.P, Baezconde-Garbanati, L., Stacy, A.W. / Californian Journal of Health Promotion 2017, Volume 15, Issue 3, Pages 1-14.

Lemoine, J., Teal, S. B., Peters, M., \& Guiahi, M. (in press). Motivating factors for dual-method contraceptive use among adolescents and young women: A qualitative investigation. Contraception.

Lux, K. M., \& Petosa, R. (1994). Preventing HIV infection among juvenile delinquents: educational diagnosis using the health belief model. International Quarterly of Community Health Education, 15, 145-163.

Ma, M., Malcom, L. R., Diaz-Albertini, K., Klinoff, V. A., Leeder, E., ... Kibler, J. L. (2014). Latino cultural values as protective factors against sexual risks among adolescents. Journal of Adolescence, 37, 1215-1225.

Malcolm, S., Huang, S., Cordova, D., Freitas, D. Arzon, B. A. ... Prado, G. (2012). Predicting condom use attitudes, norms, and control beliefs in Hispanic problem behavior youth: The effects of family functioning and parent-adolescent communication about sex on condom use. Health Education \& Behavior, 40(4), 384-391.

Marín, G., Sabogal, F., Marín, B., Otero-Sabogal, R., \& Perez, Stable, E. J. (1987). Development of a short acculturation scale for Hispanics. Hispanic Journal of Behavioral Sciences, 9, 183-205.

Matson, P. A., Chung, S., Huettner, S., \& Ellen, J. M. (2014). Understanding variability in adolescent women's sexually transmitted infection-related perceptions and behaviors associated with main sex partners. Sexually Transmitted Diseases, 41(8), 475-479.

McDermott Sales, J., Milhausen, R. R., Wingood, G. M., DiClemente, R., Salazar, L. F., \& Crosby, R. A. (2008). Validation of a parent-adolescent communication scale for use in STD/HIV prevention interventions. Health Education \& Behavior, 35(3), 332-345.

Mosher, W. D., Jones, J., \& Abma, J. C. (2012). Intended and unintended births in the United States: 1982-2010. National health statistics reports, no. 55. Hyattsville: National Center for Health Statistics.

National Center for Educational Statistics (2012). Number and enrollment of public elementary and secondary schools, by school level, type, and charter and magnet status: Selected years, 1990-91 through 2010-11 [Data file]. Retrieved from https://nces.ed.gov/programs/digest/d12/tables/dt12_108.asp.

National Center for Education Statistics (2016). Public Elementary/Secondary School Universe Survey, 1990-91 through 2014-15. Washington: U.S. Department of Education, National Center for Education Statistics.

Roncancio, A. M., Ward, K. K., \& Berenson, A. B. (2012). The use of effective contraception among young Hispanic women: The role of acculturation. Journal of Pediatric and Adolescent Gynecology, 25(1), 35-38.

Smith, S. J. (2015). Risky sexual behavior among young adult Latinas: Are acculturation and religiosity protective? The Journal of Sex Research, 52(1), 43-54.

Somers, C. L., \& Ali, W. F. (2011). The role of parents in early adolescent sexual risk-taking behavior. The Open Psychology Journal, 4, 88-95.

Spitalnick, J. S., DiClemente, R. J., Wingood, G. M., Crosby, R. A., Milhausen, R. R., Sales, J. M., ... Younge, S. N. (2007). Brief report: Sexual sensation seeking and its relationship to risky sexual behavior among African-American adolescent females. Journal of Adolescence, 30(1), 165-173.

Sussman, S., Dent, C. W., \& Stacy, A. W. (2002). Project Towards No Drug Abuse: A review of the findings and future directions. American Journal of Health Behavior, 26(5), 354-365.

Tortolero, S. R., Markham, C. M., Addy, R. C., Baumler, E. R., Escobar-Chaves, S. L., Basen-Engquist, K. M. ... Parcel, G. S. (2008). Safer choices 2: Rationale, design issues, and baseline results in evaluating school-based health promotion for alternative school students. Contemporary Clinical Trials, 29, 70-82.

Valente, T. W., Ritt-Olson, A., Stacy, A., Unger, J. B., Okamoto, J., \& Sussman, S. (2007). Peer acceleration: Effects of a social network tailored substance abuse prevention program among high-risk adolescents. Addiction, 102(11), 1804-1815. 
Espinoza, L., Richardson, J.L., Ferguson, K., Chou, C.P, Baezconde-Garbanati, L., Stacy, A.W. / Californian Journal of Health

Promotion 2017, Volume 15, Issue 3, Pages 1-14.

Widman, L., Choukas-Bradley, S., Noar, S. M., Nesi, J., \& Garrett, K. (2016). Parent-adolescent sexual communication and adolescent safer sex behavior: A meta-analysis. JAMA Pediatrics, 170(1), 5261.

Williams, R. L., \& Fortenberry, J. D. (2013). Dual use of long-acting reversible contraceptives and condoms among adolescents. Journal of Adolescent Health, 52, S29-S34.

\section{Acknowledgement}

This research was supported in part by grant 5 P50 DA016094-05 from the National Institute on Drug Abuse at the National Institutes of Health.

Author Information

Lilia Espinoza, M.P.H., Ph.D.

Department of Health Science

California State University Fullerton

800 N. State College Blvd., KHS 241

Fullerton, CA 92831

Office: (657) 278-8697

E-mail: liespinoza@fullerton.edu

* corresponding author 